\title{
Roles and functions of robots in human society: implications from research in autism therapy Kerstin Dautenhahn
}

\author{
Adaptive Systems Research Group, University of Hertfordshire, United Kingdom. E-mail: K.Dautenhahn@herts.ac.uk
}

(Received in Final Form: June 12, 2002)

\section{SUMMARY}

This paper discusses robots that are operational within a human-inhabited environment. Specifically, we identify different roles that such robots can adopt, reflecting different human-robot relationships. We discuss three different roles of robots in a project where we develop a robot as a therapeutic tool for children with autism: the robot as a therapeutic playmate, the robot as a social mediator, and the robot as a model social agent. Implications of these roles that go beyond this particular project are discussed.

\section{KEYWORDS: Autism therapy; Human society; Robots.}

\section{SOCIAL ROBOTS IN THE WILD: AN OVERVIEW}

What kind of cognitive and behavioural competencies should social robots develop, in particular those robots which primarily interact with people? In order to answer this question, it is necessary to analyse the different roles a robot can play within human society.

Traditionally robots in human society played the role of machines that were primarily used in confined and clearly defined environments, with clearly specified tasks. Typical examples are the thousands of robotic machines used in manufacturing environments. Humans were, and still are, interacting with such robots in the same way as they interact with other machines, namely as operator and control personnel. If any 'relationship' exists at all with such robots, then it is the same type of relationship that we have towards our coffee machine or car. We might develop 'attachment' to them, e.g. by getting fond of a particular car or model of a car, but the relationship is not as complex, rewarding and long-lasting as relationships we have with living organisms such as human beings or other animals. The 'bond' somebody might have with his car can possibly be compared to the relationship another person has to a precious painting: admiration of particular features (colour, texture, sound, etc.), often very individual features (e.g. the sound of a much modified racing car can be unique), but the relationship remains uni-directional. Humans might project personality and character onto a car, based on the powerful mechanisms of social cognition involving anthropomorphism and attribution of intentionality and mental states, but the car itself remains a passive object, never initiating any interactions, any 'relationship' only exists in the mind of the human.
Such type of machine-like robots are very different from recent developments of robotic and software agents that operate 'in the wild' rather than 'in the factory or laboratory'. Such agents mingle with humans in virtual market places, and communicate and interact with humans and with each other in increasingly sophisticated ways, strongly inspired by research on human-human social behaviour. Moreover, many of such agents are used in contexts where their main or primary purpose is to change the attitude, behaviour or opinions of humans. Persuasive technology is a term that has been used for such type of technology. ${ }^{1}$ In contrast to other non-persuasive technologies, "persuasive computing technology is a computing system, device, or application intentionally designed to change a person's attitudes or behaviour in a predetermined way." The functional triad of computer persuasion ranges from technology as tools (see examples above of machinelike robots) to media (e.g. virtual environments) to social actors, where agents can adopt animate characteristics, play animate roles, and follow social dynamics for the purpose of creating relationships with humans and invoke social responses. Socially intelligent agents in general, and social robots which this paper discusses in particular, are persuasive technologies and therefore issues of design, credibility, ${ }^{2}$ and ethics of persuasive technology $y^{3}$ also apply to them, in particular to the new generation of highly interactive 'social' software and robotic agents.

Increasingly new technology is used in educational and therapeutic contexts, among them Socially Intelligent Agents, i.e. agents that show aspects of human-style intelligence, ${ }^{4,5}$ e.g. multi-modal interfaces that mimic people's verbal, non-verbal and affective skills in social interactions. Socially intelligent agents research has resulted in a variety of different software and robotic systems that can successfully interact with humans (for an overview see reference [6]). New classrooms are designed, involving computer technology in order to facilitate learning, creativity and collaboration among children. The Nimis project gives an example where virtual worlds are designed as places of imagination, virtual and interactive theatres where children can create and explore their own stories. ${ }^{7}$ Carmen's Bright Ideas is an interactive animation that is simulating a counselling session for mothers whose children undergo cancer treatment. ${ }^{8}$ It is hoped, that by getting engaged in the scenario, users empathise with the animation's characters and can reflect on their own situation by assisting the virtual characters in their decisions. For many years LOGO/LEGO systems with physical or simulated robots have been used in 
education, supporting an exploratory, constructionist approach towards learning. ${ }^{9}$ In recent years a new generation of interactive social robots are designed as research platforms $^{10}$ toys (e.g. Sony's Aibo ${ }^{11}$ or educational tools. $\left.{ }^{12,13}\right)$. Such robots are specifically designed for interactions with humans, and often interactivity is the primary purpose. Social robots are therefore clearly different from service robots that may or may not interact with people, but which above all are primarily designed for a particular purpose such as serving as a tour guide. ${ }^{14}$ An interesting interactive robotic research platform is Kismet, ${ }^{10}$ a humanoid head that can generate expressive social interactions with humans. Humans interacting with Kismet are put into the position of a caretaker interacting with an 'infant' robot. It was shown that many humans responded to the robot in similarly supportive and emotional ways as they would behave towards a human infant. Such socially 'meaningful' interactions can be regarded as a stepping-stone for the development of social relationships between a robot and a human. The current version of Kismet does however not learn, memorise or adapt to particular users, a necessary prerequisite for individualised robot-human interactions that might give rise to 'relationships' (from the point of view of the user).

Another interesting example of social robots are the Robota dolls. ${ }^{15}$ They are humanoid robots developed as interactive toys for children and are used as research platforms in order to study how a human can teach a robot, using imitation, speech and gestures. Increasingly, robotic platforms are developed as interactive playmates for children (e.g. reference [12]). Besides commercial purposes (see Sony's Aibo robot), interactive robotic systems can potentially be utilised as learning environments and in therapy applications, as studied in the Aurora project (described later).

Note, that psychological/cognitive concepts such as 'social relationship', 'attachment', etc. that are used in this paper with respect to human-robot interactions are not meant to claim that the robots discussed in this paper actually possess cognitive, social, emotional and behavioural capacities comparable to human beings. For the purpose of this paper we discuss robot behaviour mainly from the perspective of human users and observers, regardless of whether one adopts a strong or weak notion of robotic intelligence and cognition. This paper does therefore not address the issue of whether robots (at present or in future) genuinely are social, or whether they just mimic (let alone the deeper question of how difficult 'just mimicking' is). What counts in the context of this paper is that humans do indeed and have always been developing 'social' relationships with objects in the world around them, and get attached to these objects. This tendency is particularly well developed with regard to biological or artificial 'agents'. ${ }^{16}$ Humans are employing a rich world of fantasy, imaginative and empathic skills in order to anthropomorphise (and understand/learn about) the world, no matter whether the object of attention is a computer, a beetle, a rat, a human being, or a robot. Thus, we assume that a human can develop a social relationship with a robot even when the robot's cognitive, behavioural and interactive capacities are much simpler than those of any human being or any other social animal. However, different types of relationships can exist along the spectrum that ranges from treating a robot as a machine to perceiving it as a social and persuasive agent. Such types of relationships and roles of robots in human society are the focus of this paper. Other research studies the development of architectures and designs for social robots, e.g. references [10] and [15]. See reference [17] for philosophical discussions on anthropomorphism and attribution of intentionality and more recent discussions on anthropomorphism and Socially Intelligent Agents in references [16] and [18].

\section{ROLES OF ROBOTS IN HUMAN SOCIETY}

In reference [19, p. 3] the following definitions for service or personal robots are discussed:

"A service robot is a robot that operates partially or fully autonomously to perform services useful to the well-being ... of humans and equipment. They are mobile or manipulative or a combination of both".

"A service robot is a freely programmable mobile device carrying out services either partially or fully automatically. Services are tasks that do not serve the direct industrial manufacture of goods, but the performing of services for humans and equipment".

Schraft and Schmierer ${ }^{19}$ give a list of scenarios for the employment of robots. Table I analyses these scenarios with respect to robot's (social) abilities, the nature of contact with humans, and the robot's functionalities, and the robot's role in society.

Please note, that the list in Table I, from top to bottom, also reflects decreasing levels of automation, and increasing levels of human-robot interactivity. Thus, it reflects the transition from viewing a robot as a machine or tool to viewing it as a 'social robot', namely a robot that can use social skills in robot-human interaction.

The following paragraphs discuss in more detail the scenario of social robots in therapy, focusing on a particular project that addresses autism therapy. In order to understand the particular requirements and constraints of this application domain, we first give a brief introduction to autism.

\section{CONTEXT OF APPLICATION AREA: AUTISM}

The autistic disorder is defined by specific diagnostic criteria, specified in DSM-IV (Diagnostic and Statistical Manual of Mental Disorders, American Psychiatric Association, 1994). Individuals with autism present with a broad spectrum of difficulties and abilities, and vary enormously in their levels of overall intellectual functioning. However, all individuals diagnosed with autism will show impairments in the following three areas:

(i) Qualitative impairment in social interaction (difficulty with social relationships, for example appearing aloof and indifferent to other people, inappropriate social interactions, inability to relate to others in a meaningful way, impaired capacity to understand other's feelings or mental states).

(ii) Qualitative impairments in communication (difficulty with verbal and non-verbal communication, for exam- 
Table I. Discussion of application domains of robots and requirements on social skills. In order to focus discussions the analysis directly refers to example applications. Note, on each of these levels we can find autonomous, semi-autonomous or remotely controlled robots.

\begin{tabular}{|c|c|c|c|c|}
\hline Application domain & Contact with humans & Functionality of robot & $\begin{array}{l}\text { Role of robot in } \\
\text { society }\end{array}$ & $\begin{array}{l}\text { Requirements on social } \\
\text { skills }\end{array}$ \\
\hline $\begin{array}{l}\text { Surveillance, sorting, } \\
\text { underwater, inspecting and } \\
\text { renovating in hazardous } \\
\text { environments, space } \\
\text { Example: Mars Rover }\end{array}$ & None, or remote & Clearly defined & $\begin{array}{l}\text { Machines outside } \\
\text { human society in } \\
\text { environments that are } \\
\text { dangerous or } \\
\text { inaccessible to humans }\end{array}$ & Not required \\
\hline $\begin{array}{l}\text { Refueling, agriculture and } \\
\text { forestry, construction } \\
\text { industry, cleaning, } \\
\text { firefighting } \\
\text { Example: The walking } \\
\text { forestry manipulator built by } \\
\text { Plustech Oy (Finland) }\end{array}$ & None, or brief & $\begin{array}{l}\text { Clearly defined } \\
\text { functionalites, clearly } \\
\text { defined interfaces for } \\
\text { human operators }\end{array}$ & $\begin{array}{l}\text { Machines that } \\
\text { automate work } \\
\text { previously done by } \\
\text { humans or other } \\
\text { machines }\end{array}$ & $\begin{array}{l}\text { Little required (apart } \\
\text { from clearly defined } \\
\text { human-machine } \\
\text { interfaces) }\end{array}$ \\
\hline $\begin{array}{l}\text { Office, medicine, hotel and } \\
\text { cooking, marketing } \\
\text { Examples: office mail } \\
\text { delivery or floor cleaning }\end{array}$ & $\begin{array}{l}\text { Occasional, but } \\
\text { important for } \\
\text { acceptance by humans }\end{array}$ & Clearly defined & $\begin{array}{l}\text { Machines in human- } \\
\text { inhabited environments } \\
\text { that provide services }\end{array}$ & $\begin{array}{l}\text { Little required, but } \\
\text { could help acceptance } \\
\text { by humans }\end{array}$ \\
\hline
\end{tabular}

robots such as the

autonomous floor vacuum

cleaner 2000 RoboVac, built

by Alfred Kärcher GmbH, or

the transport robot in

hospitals HelpMate

manufactured by TRC

\begin{tabular}{|c|c|c|c|c|}
\hline $\begin{array}{l}\text { Entertainment, hobbies and } \\
\text { recreation } \\
\text { Example: “pet robots" } \\
\text { (Sony's Aibo) }\end{array}$ & $\begin{array}{l}\text { Believability of } \\
\text { appearance and/or } \\
\text { behaviour of robot is } \\
\text { crucial if not the sole } \\
\text { purpose of the robot }\end{array}$ & $\begin{array}{l}\text { Increasingly systems } \\
\text { that can learn/adapt in } \\
\text { order to become more } \\
\text { robust and interesting } \\
\text { toys }\end{array}$ & $\begin{array}{l}\text { "Social robots": } \\
\text { increasingly } \\
\text { individualized (robots } \\
\text { "know their user") }\end{array}$ & $\begin{array}{l}\text { Social skills of the } \\
\text { robot and "attachment" } \\
\text { of user to robot are } \\
\text { crucial for success of } \\
\text { robot on the market }\end{array}$ \\
\hline $\begin{array}{l}\text { Nursing care, therapy, } \\
\text { rehabilitation } \\
\text { Example: ISAC humanoid } \\
\text { robot at Vanderbilt } \\
\text { University interacting with } \\
\text { people with disabilities, } \\
\text { therapeutic 'toy' robots used } \\
\text { in the AURORA project }\end{array}$ & $\begin{array}{l}\text { Close (often physically } \\
\text { close) contact }\end{array}$ & $\begin{array}{l}\text { Non-social } \\
\text { functionalities often } \\
\text { clearly defined, but } \\
\text { depending on social } \\
\text { functionality }\end{array}$ & $\begin{array}{l}\text { "Social robots": often } \\
\text { individualized (adapted } \\
\text { to user's specific } \\
\text { needs), autonomous, } \\
\text { ability to learn/adapt } \\
\text { often important } \\
\text { robots as therapy } \\
\text { "partners" or } \\
\text { therapeutic playmates }\end{array}$ & $\begin{array}{l}\text { Social skills and } \\
\text { acceptance by humans } \\
\text { are absolutely vital for } \\
\text { the robot's } \\
\text { functionalities and } \\
\text { success on the market. } \\
\text { Social skills can add } \\
\text { substantially to } \\
\text { efficiency and } \\
\text { acceptance. Safety and } \\
\text { ethical issues } \\
\text { important. }\end{array}$ \\
\hline
\end{tabular}

ple not really understanding the meaning of gestures, facial expressions or tone of voice).

(iii) Restricted repetitive and stereotyped patterns of behaviour, interests, and activities (preoccupation with stereotyped or restricted patterns of interest, significantly reduced repertoire of activities and interests, a tendency of fixation to routine and stable environments, adherence to specific, non-functional routines or rituals, stereotyped and repetitive motor mannerisms, persistent preoccupation with part of objects)

Depending on what is included in 'autism', rates of occurrence are given which range between 5-15 in 10000, although recent discussions suggest that the figures for incidence of autism might be much higher. Instead of a physical handicap which prevents people from physically interacting with the environment, people with autism have great difficulty in making sense of the world, in particular the social world. Autism is accompanied by learning difficulties in approximately 75 percent of cases. At the higher functioning end of the autistic spectrum we find people with Asperger Syndrome. Some of them manage to live independently as adults and to succeed in their profession, but only by learning and applying explicit rules in order to overcome the 'social barrier'. ${ }^{20}$ Instead of picking up and interpreting social cues 'naturally', they can learn and memorise rules about what kind of behaviour is socially appropriate during interaction with non-autistic people. Autism is not, as has long been assumed in public, a voluntary decision to retract from the world: people with autism do not have the choice to live socially or not, the decision has been made for them. 
Many theories exist trying to explain and understand the primary causes of autism at the psychological or cognitive level of explanation, ranging from theory-of-mind approaches that focus on the manipulation and representation of mental concepts (e.g. references [21] and [22]) to theories that explain autism in terms of disorders of executive functions that control thought and action (e.g. reference [23]). Much attention has recently focused on the significance of deficits in early social capacities (e.g. reference [24]), such as imitation, emotion sharing and shared attention, supporting the important role of dyadic child-caretaker interactions in early development. See e.g. reference [25] for more backgound information on autism is available.

\section{AURORA: SOCIAL ROBOTS IN AUTISM THERAPY}

For many years computer and (more recently) virtual environment technology have been used in autism therapy. ${ }^{26-30}$ Such work shows that many people with autism interact very 'naturally' with computer technology, and that such technology provides a safe and predictable environment that can be used in an exploratory and creative manner. A few projects also investigate robotic devices. Weir and Emanuel $^{31}$ studied one child with autism who used a keyboard to control a remote-controlled robotic device. Michaud et al. ${ }^{32}$ explore a range of different robotic designs for children with autism to interact with.

Teaching methods for children with autism address therapeutic issues (e.g. eye contact, joint attention, turn taking, reading mental states and emotions) often in constrained teaching sessions where the children are explicitly and repeatedly encouraged to make eye-contact, take turns in a social setting, associate facial expressions with emotions, etc. ${ }^{33}$ Since 1998 we study in the project Aurora $^{34}$ the potential of interactive, social robots as therapeutic tools or 'toys' in autism therapy. Here, we use a single interactive robot and study different scenarios in order to analyse qualitatively and quantitatively the children's behaviour when playing with the robot. Robot-human interactions in the Aurora project are unconstrained and unstructured, the children are allowed to interact with the robot in whatever position they prefer (e.g. lying on the floor, crawling, standing), they are also free to choose how they interact with the robot (touching, approaching, watching from a distance, picking it up, etc.). Interference is only necessary if the child is about to damage the robot or if the child (by pressing buttons) switches off the robot so that it needs to be restarted. Such conditions are much different from other projects on robot-human interaction where the human is expected to interact with the robot while adopting a particular position and orientation towards the robot (e.g. sitting face-to-face in close distance to an interactive robot that is not moving significantly in space). The mobile robot that we are using in the Aurora project allows unconstrained, full-body interactions. In the Aurora project we developed analysis techniques that are necessary to describe quantitatively and qualitatively robot-human interactions. Two techniques are described in reference [35]. One technique quantitatively analyses and statistically evaluates microbehaviours in the interactions of the children with the robot. The method is inspired by a technique originally developed for studying how a child with autism interacts with an adult. ${ }^{36}$ The other approach uses Conversation Analysis (CA) which is widely used in studies on humanhuman dialogues and interactions. ${ }^{37}$ Here, we use CA in order to analyse in more detail interaction and communication in context.

The children who are interacting with the robot are between 8-12 years of age, including children who are nonverbal, i.e. they cannot use language or usually do not use language. The particular challenges faced in the Aurora project, in the broader context of rehabilitation/therapy, together with a more detailed discussion of therapeutical issues involved, are given in references [38] and [39]. The following paragraphs give a brief summary of the project's achievements.

The first phase of the Aurora project established with 5 children that (a) the robot is safe for the children to use, (b) the children are not afraid of the robot, (c) the children are sufficiently motivated to interact with the robot over a period of ten minutes or longer, (d) the children are more interested in the robot in 'reactive' mode in comparison to the robot showing rigid, repetitive, non-interactive behaviour, (e) the children have no problems coping with the robot behaving reactively but not completely predictable. In these trials the robot showed a few basic behaviours of approach and avoidance. ${ }^{38}$

In the second phase with 18 children, we investigated whether the children behave differently towards the robot as opposed to a non-interactive toy (see Figure 1). For this purpose a quantitative evaluation technique was developed, based on the analysis of micro-behaviours. Results showed that most children showed more interest in the robot (in terms of gaze, attention, etc.) and were more engaged in interactions with the robot than with the toy. It was therefore established that the robot can engage the children with autism in interaction dynamics that are important to social interactions in general and that future trials can be based on, e.g. turn-taking games. ${ }^{40}$

In the third phase we investigated 3 pairs of children (see Figure 2). We found that the particular kind of social interactions among the children in the presence of and during interactions with the robot reflects their social interaction outside the classroom. This established that interactions with the robot in the pair-trials were not 'artificial', so future trials can build on such 2-children scenarios. Also, interesting interaction patterns involving the two children and the robot could be observed, see Table II, such as 'imitation', pointing and turn-taking. ${ }^{41}$

The next section will discuss in more detail the role of the robot in the Aurora project.

\section{ROLES OF THE ROBOT IN THE AURORA PROJECT}

First of all, and different from roles of service robots discussed in section 2, the role of the robot in the Aurora project is primarily and fundamentally social: it does not have any other function than interacting with children, and 


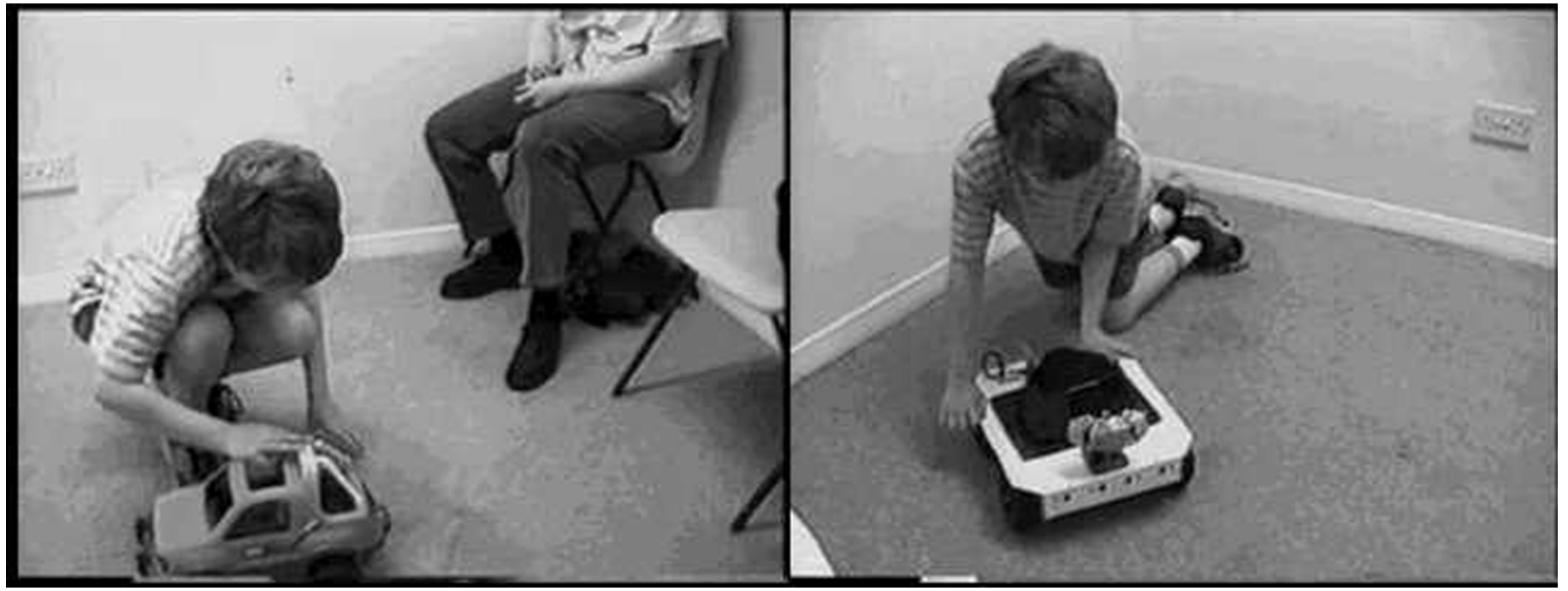

Fig. 1. The comparative study that investigated quantitative differences in robot-human interactions. A child with autism playing with a non-interative toy truck (left) and the mobile robot (right).

guiding and structuring these interactions in a therapeutically beneficial way. Three different roles of the robot are investigated (our current research focuses on the first two roles).

The robot as a persuasive machine (a therapeutic playmate). Our basic approach in the Aurora project is the one-child-one-robot scenario, namely a set up where one child at a time is interacting with the robot. The scenario is a social set up though, since other adults (experimenters and a teacher) are present. However, no other child is interacting with the robot. Here, we are interested in the robot's role as a therapeutic teaching device, a tool that can be used to teach children with autism basic social interaction skills. Since the context is playful rather than adopting a strict teaching procedure, the most important requirements for the robot are to be

(a) interesting enough to catch and maintain the child's attention for an amount of time suitable to the therapeutic context (such as 4-10 minutes minimum), so that

(b) the robot can engage the child in therapeutically relevant interactions until the trial is ended (child has to go back to class or gets bored).

The robots we use are programmed according to a behaviour-based design approach. ${ }^{42}$ Accordingly, robothuman interactions are not predefined but emerging from the robot's and the child's actions and interactions. However, the robot is equipped with basic behavioural skills such as turn-taking and following, in order to exercise simple dynamic interaction skills. Desirable social skills for the robot in the long-term are the ability to

- individually recognise and distinguish between different children

- adapt and modify its behaviour repertoire according to the social context (child's abilities, progress, interests, etc.), maintaining an interaction history

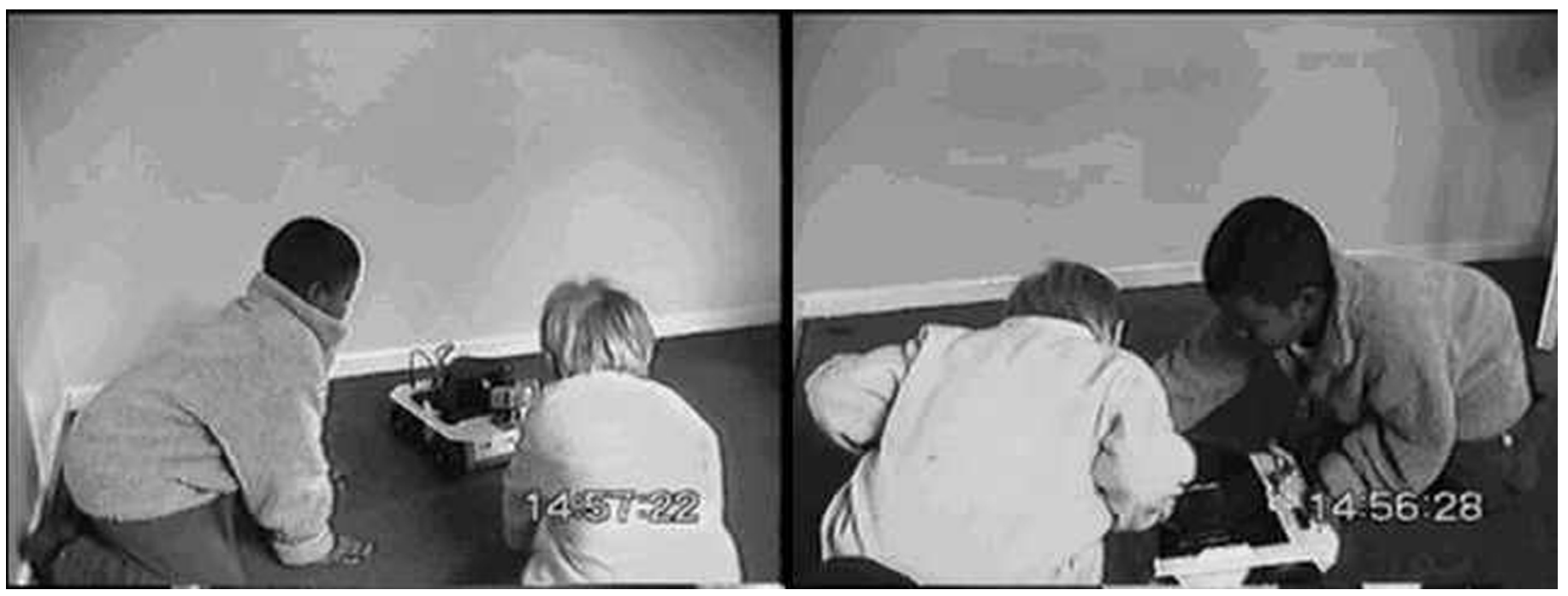

Fig. 2. The two-child-one-robot case study: two children with autism are shown playing with the robot. The trials investigated the role of the mobile robot as a serial mediator. 
Table II. Summary of the two-children-one-robot case study. The children were paired up by the teachers according to mutual familiarity and social/communication abilities. Although only three pairs were studied, interesting differences in how the children are playing with each other and the robot can be identified. This case study clearly shows how a robot can mediate play and interactions among children with autism. Further studies need to investigate whether the robot can improve children's social play skills.

\begin{tabular}{|c|c|c|c|}
\hline Social abilities (in group) & Interest level & Play-style & Robot-directed behaviours \\
\hline Highest & $\begin{array}{l}\text { High interest in robot which is a } \\
\text { very strong focus of attention } \\
\text { and curiosity during the whole } \\
\text { trial, good verbal and } \\
\text { communication skills used to } \\
\text { interact with adults (robot- } \\
\text { centered communication) }\end{array}$ & $\begin{array}{l}\text { Social play: playing and } \\
\text { communicating with each other, } \\
\text { the robot, and the adults present } \\
\text { Social learning/teaching: } \\
\text { Experimenter instructs one } \\
\text { child how to chase robot, the } \\
\text { child instructs the other child }\end{array}$ & $\begin{array}{l}\text { Exploratory and interactive play } \\
\text { with robot (touching, operating, } \\
\text { etc.), interest in chasing, } \\
\text { following and robot's speech, } \\
\text { questioning experimenters } \\
\text { about robot's skills, great } \\
\text { interest in "what robot should } \\
\text { do", etc. }\end{array}$ \\
\hline Medium & $\begin{array}{l}\text { Little interest in people, varied } \\
\text { interest in robot: one child with } \\
\text { high interest in car park visible } \\
\text { through the room's window, the } \\
\text { other child treating people as } \\
\text { "audience" }\end{array}$ & $\begin{array}{l}\text { Non-social play: playing with } \\
\text { robot simultaneously, but not } \\
\text { playing with each other, } \\
\text { "accidental" interaction when } \\
\text { both competed for robot's } \\
\text { "attention", teacher } \\
\text { occasionally had to give } \\
\text { guidance/calm children down } \\
\text { when children grew bored }\end{array}$ & $\begin{array}{l}\text { Interest in robot's destructive } \\
\text { skills, cornering robot, shouting } \\
\text { at robot to get it to move, } \\
\text { operating robot }\end{array}$ \\
\hline Lowest & $\begin{array}{l}\text { Both children interested in } \\
\text { robot }\end{array}$ & $\begin{array}{l}\text { Non-social play: } \\
\text { One child dominates } \\
\text { interaction, open competition } \\
\text { for robot, using social skills in } \\
\text { obstruction of other child, e.g. } \\
\text { "leave him alone" }\end{array}$ & $\begin{array}{l}\text { Giving vocal commands and } \\
\text { directions to robot, operating } \\
\text { robot }\end{array}$ \\
\hline
\end{tabular}

- gradually guide the child through different types of interactions where therapeutic effects can be expected

Such skills would address requirements identified in Table I.

Note, that in this scenario a certain degree of 'attachment' of the child towards the robot can be helpful, although the robot should of course not become a substitute for human beings. However, the more the child is interested in interacting with the robot, the longer we can expect the interactions to last, which increases the chances of therapeutic effects.

The robot as a social mediator. A second very important role of the robot that was already mentioned in section 4 is the robot's role of a social mediator, a tool that mediates (encourages and facilitates) social behaviour among children, and among children and adults. In designing such a social mediator it is important to study carefully how children with autism interact with the robot, how their particular difficulties and abilities influence the interactions, and how the robot can be used so as to encourage particular 'desirable' types of interactions, i.e. interactions that children with autism might generalise, and that then could help in daily interactions with humans outside the classroom context. Using robots as machines that can mediate between people is a challenging task, a task where ultimately, when successful, the robot would 'disappear', and would no longer be needed. Once children with autism show improved interaction skills, the need to interact with the robot would become obsolete. This scenario gives an example where strong attachment of children with the robot are actually not necessarily desirable and could indeed be counterproductive to the therapeutic efforts. The novel role of robots as social mediators that we suggest needs to be investigated much further, although preliminary results are positive and encouraging. ${ }^{41}$

Robots as model social agents. A child who grows up immersed in human society and culture does not have to learn social skills 'academically', she learns them in daily practise by observing and interacting with her direct social environment, including caretakers, other adults, peers, all are very social beings and excellent examples of how, when, and why to use which social skills. A novel scenario for social robots that we propose is to use robots as social 'actors', in a literal sense, namely as agents that are enacting social stories, agents that can be observed, and that one can potentially learn from about the complexity but also about the structure of social behaviour. ${ }^{43}$

The actor-metaphor we put forward in this paper is meant in the sense of actors who enact stories and are being watched by humans, similar to theatre-in-education (TIE) initiatives where actors perform educationally relevant stories in schools. While human actors use a huge range of expressions of behaviour, motivations and emotions, robots could be actors that are much simpler, more predictable, and thus more suitable for an autistic 'audience'.

What type of stories could robots perform? An actor performing in a traditional theatre play is strongly following a more or less rigid script. In contrast, natural human-human interactions in the wild are often very context and persondependent variations of a common theme rather than stereotypical repetitions. Thus, if slowly improvisational 
elements are added to the 'play', they could demonstrate patterns but also variations of human-human interactions, including both positive as well as negative aspects of human social behaviour. Additionally, watching a theatre play in the theatre rather than on television is certainly more enjoyable because of the location, and the felt 'presence' of the actors. Thus, what could be the special role of robots as actors, as opposed to watching theatre plays (live or recorded, remotely or at location), or watching plays staged in puppet theatres or within virtual environments? What robots can add to the theatre metaphor is interactivity, the possibility to simultaneously be a spectator and participant in a theatre play. For example in the context of using robots in autism therapy, robots could slowly engage the child in interactions with itself and other robots, becoming a member of the group. Investigating this scenario will be one possible future aim of the Aurora project. It involves a number of very challenging problems in terms of robot design, design of the 'play', and designing the interactive aspects of involving the child.

\section{CONCLUSION: WHY SHOULD HUMANS INTERACT WITH ROBOTS?}

The sections above discussed different roles of robots in human society, and in the context of autism therapy, summarised in figure 3. However, I believe that the implications of the above are broader and can be applied to various other areas where social robots are intended to be used 'in the wild'.

(i) Robots as persuasive machines need to be able to engage people in social interaction, ${ }^{10}$ and they need to have their own agenda, an agenda that will ultimately change the human's beliefs, attitudes, or behaviour. This influence can be therapeutic, as it is the goal in the Aurora project discussed above, but it might also be used for purely commercial or other manipulative purposes (similar to human sales assistants who sometimes succeed to sell us a product we don't need).

(ii) Robots as social mediators need to be socially embedded, part of and 'aware' of the social environment in order to be really effective. In reference [44] we discuss requirements for building interaction-aware machines. Such machines need to be able to perceive and act upon structures and dynamic patterns of social interactions that they observe and that they are part of. To give an example: the study of proxemics ${ }^{45}$ is concerned with the communicative value of space and movements. Specifically, orientation and distance of people in social interactions play crucial roles in regulating and expressing, e.g. degrees of familiarity and intimacy (see social spaces), as well as aspects of attention, intention and emotions in social interaction. Robots need to be aware of the social space of interaction, and need to be able to act within it.

(iii) Robots that are social actors could not only be models of social interaction that can be exploited in therapy, they could also use these acting abilities for other purposes, such as
- Through interactions with other robots of the same kind, they can demonstrate their particular style of interaction, in this way advertising their competencies as suggested in reference [46]. Getting the message across to the user what an agent can do and what it cannot do is a common problem of agent designers. We suggest that instead of leaving it up to the human to find out how to interact with a machine (typically by initial anthropomorphic assumptions and subsequent trial and error learning), the machine should show explicitly its competencies.

- Pantomime is an interesting type of acting, a very powerful means of non-verbal communication. Exploiting these directions could lead to robots that are 'true actors', i.e. possessing a variety of means how they can express or 'encode' a certain message, and choosing the one that is most appropriate in the context, suitable to a particular task, acceptable to humans, and adaptive in order to meet specific needs of individual humans. First attempts of using robots as 'performers' are underway, in particular targeted towards entertainment applications. ${ }^{47}$

Note, that these above mentioned skills can be integrated in one and the same machine. Such a machine could adopt various roles, resulting in a machine with tremendous social competencies and adaptivity, so that humans might very much enjoy interacting with them. Usually it is assumed that humans are interested in interacting with a social robot, e.g. in entertainment where people might want to play with a robot that looks like a dog (approximately) and shows some rudimentary competencies of a dog. However, it is unlikely that such machines that have no notion of social space and social structure can survive effectively in human society for a long time (see Figure 3).

In this paper we discussed different roles of robots, focusing on our particular application domain of autism therapy, but also discussing implications for the wider context of social robots in the wild. It is more and more acknowledged that robots need to be able to become part of human society, but what does it mean specifically? In this paper we identified different roles of robots in human society, some of them going beyond the traditional robot-asmachine or robot-as-competitor scenarios. We suggest that a detailed analysis of application domains and the (social) requirements of robots in these domains might allow us to identify a variety of different roles. Exploring the space of sets of requirements which Aaron Sloman called niche space $^{48}$ and exploring corresponding mappings between the design space of social robots and the niche space, might open up a variety of new opportunities and challenges for robotics research, and help to integrate robotic technology in human society.

A major challenge that we identified is how to design socially embedded machines, machines that are 'aware' of the social context they are embedded in. As discussed in reference [44], research is just beginning to address how robots can be socially embedded. One of the difficulties of work along these lines is that it is a highly interdisciplinary field, at the cross-section of cultural studies, social sciences, 
a)

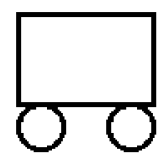

b)

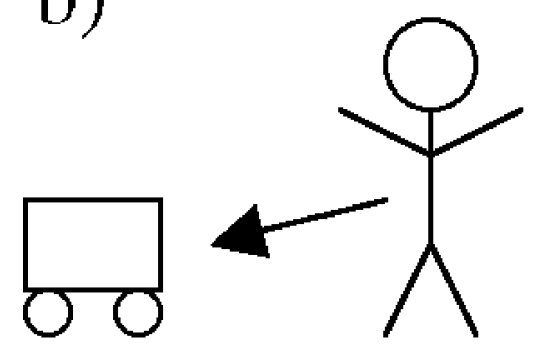

C)

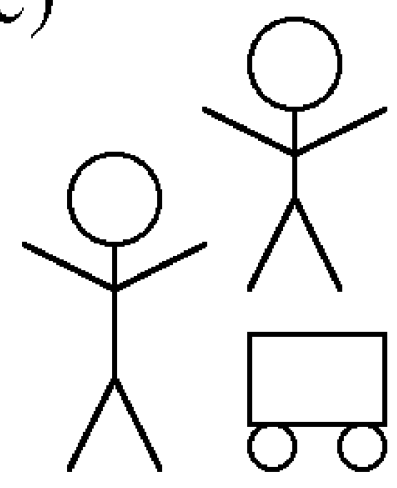

d)

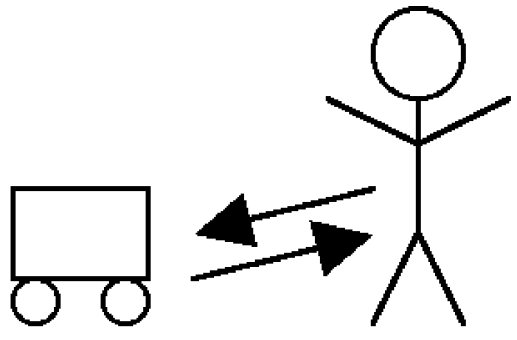

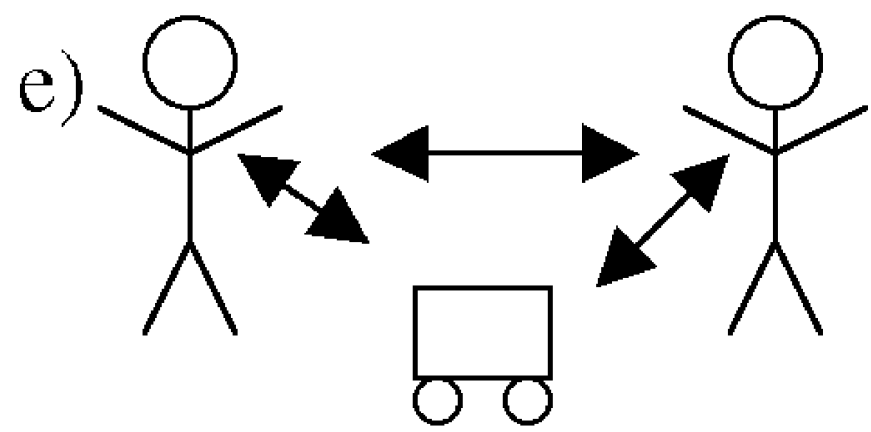

f)

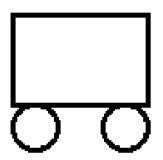

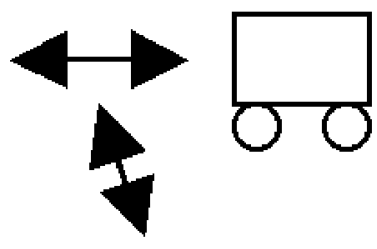

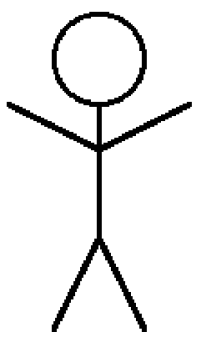

Fig. 3. Different roles of robots in human society. Left top: the autonomous robot operating without significant contact with humans. Left middle: the robotic tool used by human operators. Left bottom: the robot operating in a human-inhabited environment. The roles depicted on the left are discussed in section 2. The roles on the right are discussed in section 5 and emerged from research in the Aurora project. Right, top: the robot as a persuasive (in the case of Aurora therapeutic) machine. Right middle: the robot as a social mediator. Right bottom: the robot as a model social actor.

robotics, engineering and artificial intelligence. Models and ideas cannot simply be transferred across disciplinary boundaries, it requires the synthesis and integration of diverse sources of knowledge and skills, involving the development and adaptation of new methods, methodologies, design and evaluation techniques, and the training of a new generation of researchers qualified in this area. Ultimately we can expect that it requires the emergence of a new science.

\section{ACKNOWLEDGEMENTS}

This Aurora project is supported by an EPSRC grant (GR/ M62648). The mobile robotic platform used is kindly donated by Applied AI Inc. Many thanks to friends and members of the Aurora project for discussions on using robots in autism therapy. The trials mentioned in section 4 form part of Iain Werry's PhD work, co-sponsored by the author and William Harwin. Thanks to the organisers David McFarland and Owen Holland, and the participants of the 
workshop "Social Robotics" in Puerto Chico A, Lanzerote, Spain, June 29th to July 4th, where some of the issues presented in this paper were discussed.

\section{References}

1. B.J. Fogg, "Introduction: Persuasive Technologies," Сотmunications of the ACM 42(5), 27-29 (1999).

2. S. Tseng and B.J. Fogg, "Credibility and computing technology," Communications of the ACM 42(5), 39-44 (1999).

3. D. Berdichevsky and E. Neunschwander, "Toward and ethics of persuasive technology," Communications of the ACM 42(5), 51-58 (1999).

4. K. Dautenhahn, "The art of designing Socially Intelligent Agents - Science, fiction, and the human in the loop," Special Issue "Socially Intelligent Agents", Applied Artificial Intelligence Journal 12, 7-8, 573-617 (Oct., Dec., 1998).

5. K. Dautenhahn, "Embodiment and interaction in socially intelligent life-like agents," In: (C.L. Nehaniv, Ed.), Computation for Metaphors, Analogy and Agent, Springer Lecture Notes in Artificial Intelligence, Springer (1999) Vol. 1562, pp. 102-142.

6. K. Dautenhahn (Ed.), Human Cognition and Social Agent Technology (John Benjamins Publishing Company, 2000).

7. I. Machado and A. Paiva, "The child behind the character," In: (K. Dautenhahn, Ed.), Proc. Socially Intelligent Agents - The Human in the Loop (AAAI Press, Technical report FS-00-04, 2000) pp. 102-106.

8. S.C. Marsella, W.L. Johnson and C. LaBore, "Interactive pedagogical drama," Proc. of the Fourth International Conference on Autonomous Agents, June 3-7, Barcelona, Spain, ACM Press (June, 2000) pp. 301-308.

9. S. Papert, Mindstorms: Children, computers, and powerful ideas (Basic Books, New York, 1980).

10. C. Breazeal and B. Scassellati, "Infant-like social interactions between a robot and a human caretaker", Adaptive Behavior 8(1), 49-74 (2000).

11. Aibo, URL www.aibo.com Last referenced 21st February 2002.

12. A. Druin and J. Hendler (Eds), Robots for Kids: Exploring new technologies for learning (Morgan Kaufrnann PubIishers, 2000).

13. M. Cooper, D. Keating, W. Harwin and K. Dautenhahn, "Robots in the classroom - Tools for accessible education," Proc. AAATE Conference, The 5th European Conference for the Advancement of Assistive Technology (C. Bühler and $\mathrm{H}$. Knops, Eds.), Düsseldorf/Germany, IOS Press (1999) pp. 448-452.

14. S. Thrun, M. Beetz, M. Bennewitz, W. Burgard, A.B. Creemers, F. Dellaert, D. Fox, D. Hahnel, C. Rosenberg, N. Roy, J. Schulte and D. Schulz, "Probabilistic Algorithms and the Interactive Museum Tour-Guide Robot Minerva," Int. J. Robotics Research 19(11), 972-999 (2000).

15. A. Billard, "Play, dreams and imitation in Robota," In: (K. Dautenhahn, Ed.), Proc. Socially Intelligent Agents - the Human in the Loop, AAAI Fall Symposium, Technical Report FS-00-04, AAAI Press (2000) pp. 9-12.

16. K. Dautenhahn, "I could be you - the phenomenological dimension of social understanding," Cybernetics and Systems Journal 28(5), 417-453 (1997).

17. D.C. Dennett, The Intentional Stance (MIT Press, 1987).

18. P. Persson, J. Laaksoiahti and P. Lönnqvist, "Anthropomorphism - A multi-layered phenomenon," In: (K. Dautenhahn, Ed.), Proc. Socially Intelligent Agents - The Human in the Loop, AAAI Press, Technical report FS-00-04 (2000) pp. 131135.

19. R.D. Schraft and G. Schmierer, Service Robots (A.K. Peters, Ltd., 2000).

20. T. Grandin and M.M. Scariano, Emergence. Labeled autistic (Warner Books, 1996).
21. A.M. Leslie, "Pretense and representation: the origins of 'theory of mind'," Psychological Review 94(4), 412-426 (1987).

22. S. Baron-Cohen, Mindblindness (A Bradford Book, MIT Press, 1995).

23. J. Russell, Autism as an Executive Disorder (Oxford University Press, 1997).

24. S.J. Rogers and B.F. Pennington, "A theoretical approach to the deficits in infantile autism," Development and Psychopathology 3, 137-162 (1991).

25. R. Jordan, Autistic Spectrum Disorders - An introductory handbook for practitioners (David Fulton Publishers, London, 1999).

26. K.M. Colby and D.C. Smith, "Computers in the treatment of nonspeaking autistic children," Current Psychiatric Therapies 11, 1-17 (1971).

27. D. Strickland, "A virtual reality application with autistic children," Presence: Teleoperators and Virtual Environments 5(3), 319-329 (1996).

28. S. Powell, "The use, of computers in teaching people with autism. In: Autism on the Agenda (papers from a National Autistic Society Conference. London, NAS,1996).

29. D. Moore, "Computers and people with autism," Communication 20-21 (1998).

30. S. Parsons, L. Beardon, H.R. Neale, G. Reynard, R. Eastgate, J.R. Wilson, S.V. Cobb, S.D. Benford, P. Mitchell and E. Hopkins, "Development of social skills amongst adults with Asperger's Syndrome using virtual environments: the "AS Interactive' project," Proc. 3rd Interl. Conf. Disability, Virtual Reality \& Assoc. Tech., Aighero, Italy (2000) pp. 163-170.

31. S. Weir and R. Emanuel "Using Logo to catalyse communication in an autistic child," DAI Research Report No. 15 (University of Edinburgh, 1976).

32. F. Michaud and Catherine Théberge-Turmel, "Mobile robotic toys and autism," In: (K. Dautenhahn, A. Bond, L. Cañamero and B. Edmonds, Eds.), Socially Intelligent Agents - Creating relationships with computers and robots (Kluwer Academic Publishers, 2002) pp. 125-132.

33. P. Howlin, S. Baron-Cohen and J. Hadwin, Teaching Children with Autism to Mind-read (John Wiley and Sons, 1999).

34. Aurora, URL, http://www.aurora-project.com/ (Last referenced 21st February, 2003).

35. K. Dautenhahn, I. Werry, P. Dickerson, J. Rae, P. Stribling and B. Ogdery, "Robotic Playmates - Analysing interactive competencies of children with autism playing with a mobile robot," In: (K. Dautenhahn, A. Bond, L. Cañamero, B. Edmonds, Eds.), Socially Intelligent Agents - Creating relationships with computers and robots (Kluwer Academic Publishers, 2002) pp. 117-124.

36. C. Tardiff, M.-H. Plfumet, J. Beaudichon, D. Waller, M. Bouvard and M. Leboyer, "Micro-analysis of social interactions between autistic children and normal adults in semi-structured play situations," Int. J. Behavioural Development 18(4), 727-747 (1995).

37. I. Hutchby and R. Wooffitt, Concentration Analysis: Principles, Practices and Applications (Polity Press, Cambridge, 1988).

38. K. Dautenhahn and I. Werry, "Issues of robot-human interaction dynamics in the rehabilitation of children with autism," In: (J.-A. Meyer, A. Berthoz, D. Floreano, H. Roitblat and S.W. Wilson, Eds) Proc. From Animals To Animats. The Sixth International Conference on the Simulation of Adaptive Behavior (2000) pp. 519-528.

39. K. Dautenhahn and I. Werry, "The AURORA project: Using mobile robots in autism therapy," Learning Technology Online Newsletter, publication of IEEE Computer Society Learning, Technology Task Force (LTTF), 3(1), (January 2001) (Online Journal Publication).

40. I. Werry, K. Dautenhahn and W. Jarwin, "Investigating a robot as a therapy partner for children with autism, Proc. 6th European Conference for the Advancement of Assistive Technology, AAATE 2001, Ljubljana (Slovenia, 2001). 
41. I. Werry, K. Dautenhahn, B. Ogden and W. Harwin, "Can social interaction skills be taught by a social agent? The role of a robotic mediator in autism therapy," In: (M. Beynon, C.L. Nehaniv and K. Dautenhahn, Eds.), Cognitive Technology: Instruments of Mind (Proc. CT2001, Springer Verlag, LNAI 2117 (2001) pp. 57-74.

42. R.C. Arkin, Behavior-based Robotics (MIT Press, Cambridge, Mass., London, England, 1998).

43. K. Dautenhahn, "Robots as social actors: AURORA and the case of autism," Proc. The Third International Cognitive Technology Conference, CT99, San Francisco (August, 1999) pp. 359-374.

44. K. Dautenhahn, B. Ogden and T. Quick, "From Embodied to Socially Embedded Agents - Implications for InteractionAware Robots," Cognitive Systems Research, Special issue on
Situated and Embodied Cognition (guest-editor: Tom Ziemke) Vol. 3(3), pp. 397-428 (2002).

45. E.T. Hall The Hidden Dimension: Man's use of space in public and private (The Bodley Head Ltd, London, UK, 1966).

46. K. Dautenhahn and C.L. Nehaniv, Living With Socially Intelligent Agents: A Cognitive Technology View, chapter 16 in reference [6], pp. 415-426 (2000).

47. A. Bruce, J. Knight, S., Listopad, B., Magerko and I.R. Nourbakhsh, "Robot Improv: Using drama to create believable agents," Proc. Workshop WIRE-2000 (Pittsburgh, USA, 2000).

48. A. Sloman, "The 'semantics' of evolution: Trajectories and trade-offs in design space and niche space," In: (H. Coelho, Ed.), Progress in Artificial Intelligence (Springer Verlag, 1998) pp. 27-38. 